\title{
Improving the mechanical properties of commercial feldspathic dental porcelain by addition of Alumina-Zirconia
}

Mejora de las propiedades mecánicas de porcelana dental feldespática comercial mediante adición de Alúmina-Circona

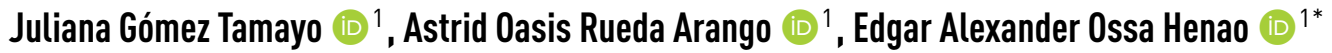 \\ ${ }^{1}$ Grupo de Investigación en Materiales de Ingeniería, Universidad Eafit. Carrera 49 \#7 Sur 50, avenida de Las Vegas. A. E. 3300. Medellín, \\ Colombia.
}

\section{CITE THIS ARTICLE AS: \\ J. Gómez, A. O Rueda and \\ E. A. Ossa. "Improving the mechanical properties of commercial feldspathic dental porcelain by addition of Alumina-Zirconia", Revista Facultad de Ingeniería Universidad de Antioquia, no. 94, pp. 67-76, Jan-Mar 2020. [Online]. Available: https : \\ //doi.org/10.17533/ udea.redin.n91a11}

\section{ARTICLE INFO:}

Received: August 23, 2018 Accepted: May 06, 2019 Available online: May 06 2019

\section{KEYWORDS:}

Dental ceramics; reinforcing agent; fracture; Hertzian contact

Ceramicas dentales; agente de refuerzo; fractura; contacto Herziano

\begin{abstract}
Dental ceramics made from Yttria stabilized tetragonal Zirconia polycrystalline (Y-TZP) with feldspathic porcelain veneers have similar mechanical and aesthetic response to natural tooth. However, cases of early failure, such as chipping or fracture in the veneering have been reported after short periods of use. The present study evaluated the feldspathic porcelain (VITA-VM9) with addition of 0.5 and $2.5 \mathrm{wt} \%$ Alumina-Zirconia as reinforcing agents. Hardness, fracture toughness, contact resistance and color variations were evaluated finding better mechanical performance on the new formulations.
\end{abstract}

RESUMEN: Las cerámicas dentales fabricadas a partir de Circona tetragonal policristalina estabilizada con Ytria (Y-TZP) con recubrimientos de porcelana feldespática tienen una respuesta mecánica y estética similar a la del diente natural. Sin embargo, se han reportado casos de falla temprana, como el astillado o fractura en el recubrimiento después de cortos períodos de uso. El presente estudio evaluó la porcelana feldespática (VITA-VM9) con la adición de 0,5 y 2,5\% en peso de Alúmina-Circona como agentes de refuerzo. Se evaluaron la dureza, la tenacidad a la fractura, la resistencia al contacto y las variaciones de color encontrando un mejor desempeño mecánico en las nuevas formulaciones.

\section{Introduction}

Natural teeth are exposed to different oral environments - affected by saliva, mucosa, food, temperature and chewing - generating alterations in $\mathrm{pH}$ that may produce in medium or long-time periods oral complications such as periodontitis, gingivitis, wear or fracture of tooth. Therefore, it has been necessary the development of

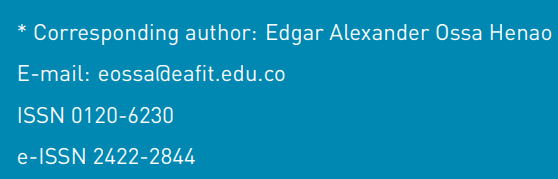


appearance, being feldspathic porcelain one of the most used for this purpose [3-5].

Several researchers have reported cases of chipping, fracture or delamination of the veneering at rates of up to $35 \%$ in periods of 2 to 5 years of operation as a result of its composition, microstructure, residual stresses and surface finish after its processing [6-8]. Thus, it has been considered imperative to increase the fracture toughness of this material, mainly by modifying its microstructure or composition [8-10].

The increase in mechanical properties, such as flexural strength and fracture toughness in vitroceramics reinforced with zirconia particles has been reported [11], also has been found that there is an increase in flexural strength with addition of alumina $\left(\mathrm{Al}_{2} \mathrm{O}_{3}\right)$ in feldspathic porcelain $[12,13]$. Despite of this mechanical improvements, an opaque color was found under both conditions, which reduces the aesthetics of the porcelain.

The effect on the mechanical properties of commercial feldspathic porcelain with addition of Alumina-Zirconia as reinforcing agents were evaluated in this work aiming at avoid the variation in the aesthetic characteristics of the veneer while improving its mechanical properties.

\section{Materials and methods}

\subsection{Materials preparation}

The procedure for specimen fabrication recommended by the manufacturers was followed in this work in order to maintain the main characteristics of the materials [14]. VITA-VM9 porcelain (VM9-2M2 Base Dentine, VITA Zahnfabrik, Bad Sackingen, Germanyl was used as base material for the elaboration of the veneering. Table 1 shows the nominal chemical composition of the material [15].

Table 1 Chemical composition of VITA-VM9 porcelain

\begin{tabular}{lc}
\hline Chemical composition & $\%$ \\
\hline $\mathrm{SiO}_{2}$ & $60-64$ \\
$\mathrm{Al}_{2} \mathrm{O}_{3}$ & $13-15$ \\
$\mathrm{~K}_{2} \mathrm{O}$ & $7-10$ \\
$\mathrm{Na}_{2} \mathrm{O}$ & $4-6$ \\
$\mathrm{TiO}_{2}$ & $<0.5$ \\
$\mathrm{CeO}_{2}$ & $<0.5$ \\
$\mathrm{ZrO}_{2}$ & $0-1$ \\
$\mathrm{CaO}$ & $1-2$ \\
$\mathrm{~B}_{2} \mathrm{O}_{3}$ & $3-5$ \\
$\mathrm{BaO}$ & $1-3$ \\
$\mathrm{SnO}$ & $<0.1$ \\
$\mathrm{Oxides}$ of $\mathrm{Mg}, \mathrm{Fe}$ y P & $<0.5$ \\
\hline
\end{tabular}

The porcelain powder VITA-VM9 was mixed with Alumina $\left(\mathrm{Al}_{2} \mathrm{O}_{3}\right)$ 99.8\% pure and Zirconia particles (3Y-TZP) (Tosoh, Japan) at two percentages of 0.5 and $2.5 \%$, having equal parts of both components; the detailed composition of the mixtures are shown in Table 2. The composite mixture only by VITA-VM9 corresponds to the standard sample (A).

Samples B and C were dissolved in ethanol and then dispersed using a sonicator (Branson) at an amplitude of $20 \%$ for 1 minute. The sonication facilitates the breakage of the agglomerates and generates good dispersion of the particles in less time of mixing in comparison with other mixing techniques such as grinding. The samples were then dried at $80^{\circ} \mathrm{C}$ in an oven type muffle (Terrigeno) for 2 hours. To the resulting formulation were added 5 diluent drops (VITA Zahnfabrik, Bad Sackingen, Germany) and the mixture was applied on cylindrical substrates 3Y-TZP with $8 \mathrm{~mm}$ of diameter and $2 \mathrm{~mm}$ of thickness. Each formulation was sintered in two steps. Initially, a layer of the formulation was applied and sintered at $950^{\circ} \mathrm{C}$ for 1 minute. After reaching room temperature, a second layer of the formulation was applied and sintered at 910 ${ }^{\circ} \mathrm{C}$ for $1 \mathrm{~min}$. Both stages were carried out in a vacuum oven (PRO 200 WHIP-MIX). With the purpose of eliminate imperfections and to facilitate microscopic observation, a polishing procedure was carried out with 15 and $6 \mu \mathrm{m}$ diamond suspension of colloidal silica and abundant water until obtaining a mirror finish and a layer thickness of 500 $\mu \mathrm{m}$ approximately.

\subsection{Visual and microscopic characterization}

The characterization of the materials and new formulations were examined using an optical microscope (Axiovert 40 MAT Zeiss), stereomicroscope (AxioCam ICc 3 Zeiss) and SEM EVO MA10 of Carl Zeiss with detector EDS X-act (Oxford).

Color difference on the samples was analyzed using UV-VIS spectrophotometry (Varian Cary 100 spectrophotometer with integration sphere). Two tests were performed for each sample.

\subsection{Mechanical characterization}

The mechanical characterization was carried out through instrumented nanoindentation tests, Vickers microhardness and monotonic Hertzian contact.

The nanoindentation tests (triboindentor, ti-9050 Hysitron) were carried out with a Berkovich diamond tip. Applied force control of $10 \mathrm{mN}$ was used with holding times of 10 $\mathrm{s}$ and two indentation matrices of $4 \times 4$ with distance of 10 $\mu \mathrm{m}$ between indentations. The results were analyzed by using the Oliver and Pharr method. These results showed 
Table 2 Composition of porcelain in study

\begin{tabular}{ll}
\hline Name & Mixture \\
\hline Sample A & VITA-VM9 \\
Sample B & VITA-VM9 + 0.5\% mixture $\left(50 \% \mathrm{Al}_{2} \mathrm{O}_{3}+50 \% 3 \mathrm{Y}\right.$-TZP) \\
Sample C & VITA-VM9 + 2.5\% mixture $\left(50 \% \mathrm{Al}_{2} \mathrm{O}_{3}+50 \% 3 \mathrm{Y}\right.$-TZP) \\
\hline
\end{tabular}

information of the Young's modulus based on the load as a function of depth.

The apparent fracture toughness ( $\mathrm{Kc}$ ) was determined from the microhardness tests with the appearance of Palmqvist cracks, calculated using Equation 1 according to [16].

$$
\mathrm{k}_{\mathrm{c}}=0.0084\left(\frac{E}{H V}\right)^{\frac{2}{5}}\left(\frac{2 F}{L}\right)\left(\frac{1}{c^{\frac{1}{2}}}\right)
$$

where $\mathrm{E}$ is Young's modulus (GPa), HV is Vickers hardness (GPa), $F$ the indentation load ( $N$ ), $L$ is the mean length of the diagonals $(\mathrm{m})$ and $\mathrm{C}$ is the length of the cracks $(\mathrm{m})$.

The results obtained from Vickers hardness and fracture toughness were analyzed statistically using an analysis of variance (ANOVA) with a Tukey test in a confidence interval of $95 \%$ and a $p$-value $\leq 0.05$. This was done in order to establish differences or similarities statistically significant between the values obtained.

Monotonic Hertzian contact tests were carried out using a universal testing machine (Instron, model 3366) with tungsten-carbide cobalt spheres (WC-Co) with a radius $(\mathrm{R})$ of $1.25 \mathrm{~mm}$. The load was applied at a constant strain rate of $1 \mathrm{~N} / \mathrm{s}$ and a holding time at maximum load of $1.00 \mathrm{~s}$ [17-19]. Once the test was completed, the indented area was analyzed using optical microscopy.

\section{Results and discussion}

\subsection{Visual and microscopic characterization}

Figure 1 shows the VITA-VM9, Al203 and 3Y-TZP powders with average particle sizes of $13.74 \mu \mathrm{m}$ (Figure 1a), $3.39 \mu \mathrm{m}$ (Figure $1 \mathrm{~b}$ ) and agglomerates of $36.87 \mu \mathrm{m}$ approximately (Figure 1c).

Figure 2 shows the visual characterization of the formulations after fabrication. A homogeneous coloration is observed over the entire surface and a minor change in translucency was observed with respect to the standard sample (Sample A) along with a porosity characteristic of this type of materials. This shows that the sonication method for the dispersion of the particles was effective in achieving a well dispersed material.

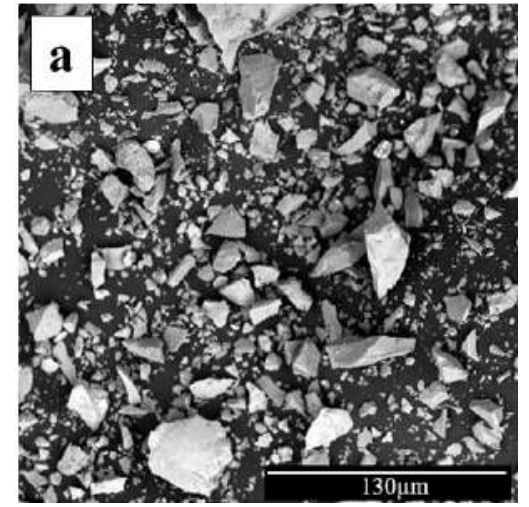

(a)

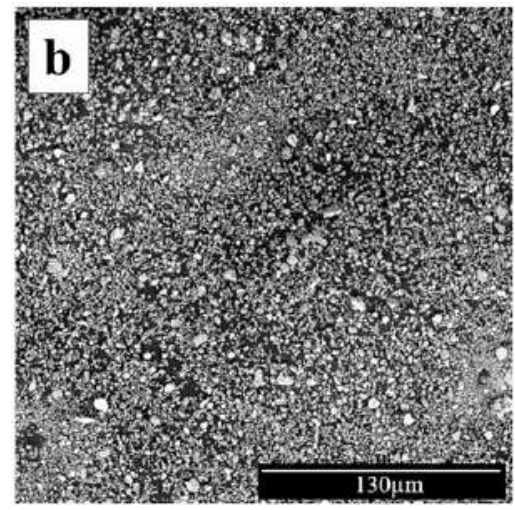

(b)

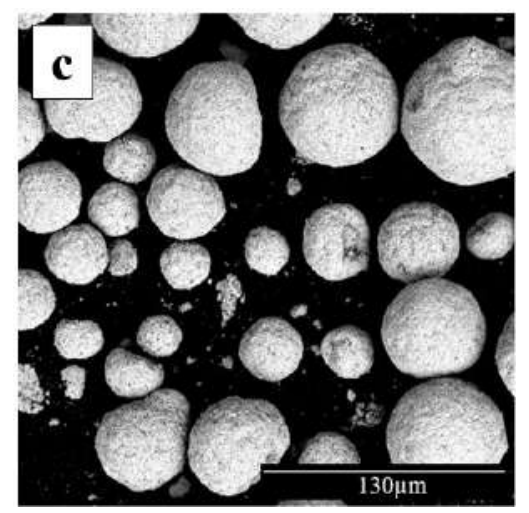

(c)

Figure $1 \mathrm{SEM}$ images of the raw materials used to obtain the new formulations. a) VITA-VM9, b) $\mathrm{Al}_{2} \mathrm{O}_{3}$ and c) 3Y-TZP

In the UV-Vis spectrophotometry tests the color coordinates of the new formulations (Table 3) and the color difference of the samples were estimated following 


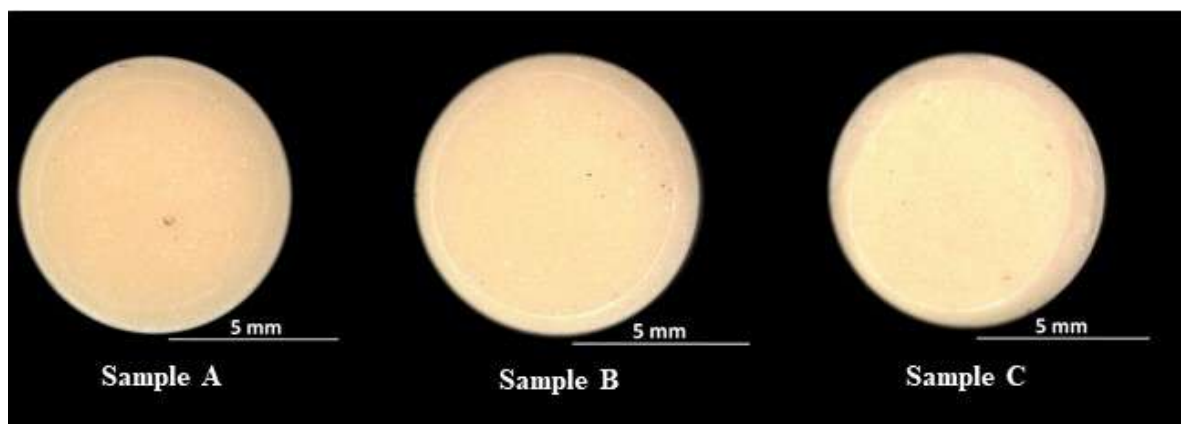

Figure 2 Surface appearance of the formulations

ISO 11664-4 (2008) [20] according to the Equation 2.

$$
\Delta \mathrm{E}^{*}=\left(\left(\Delta \mathrm{L}^{*}\right)^{2}+\left(\Delta \mathrm{a}^{*}\right)^{2}+\left(\Delta \mathrm{b}^{*}\right)^{2}\right)^{\frac{1}{2}}
$$

Figure 3 shows the values obtained, where sample $B$ is close to the standard sample A. While sample $C$ is the one that had the most distant results. From these measurements it is possible to conclude that at high percentages of mixture of $\mathrm{Al}_{2} \mathrm{O}_{3}-3 \mathrm{Y}$-TZP color changes occur with respect to the standard sample. These results are attributed to the translucency depending on the percentage, shape and particle size of the material added, in addition to the difference in the refractive index of the base material with respect to the material added [21].

Table 3 Color CIE L*a* $b$ * for the formulations

\begin{tabular}{lccc}
\hline Name & $\mathbf{L}^{*}$ & $\mathbf{a}^{*}$ & $\mathbf{b}^{*}$ \\
\hline Sample A & 79.2 & 2.6 & 18.3 \\
Sample B & 81.1 & 2.3 & 15.8 \\
Sample C & 87.3 & 1.6 & 12.6 \\
\hline
\end{tabular}

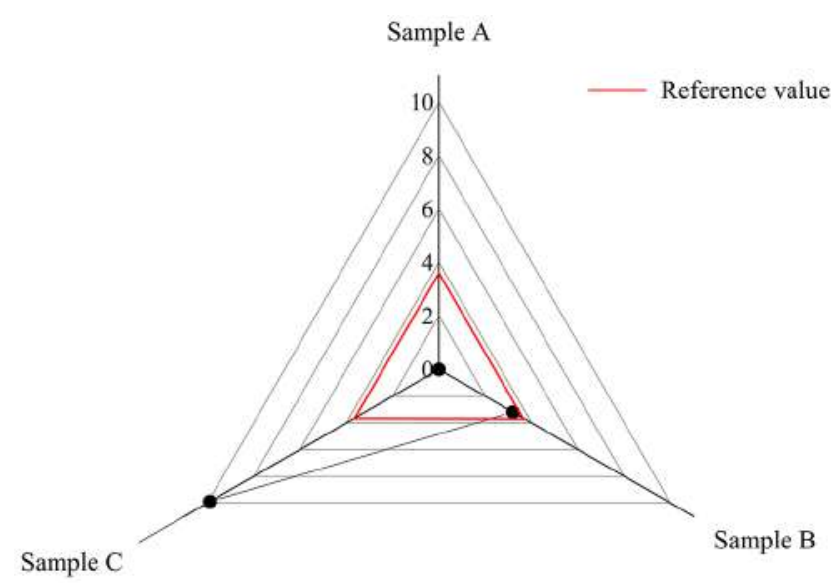

Figure 3 Color differences for formulations

On the other hand, some investigations have considered that the value of color difference by which the chromatic change is clinically acceptable is $\triangle \mathrm{E} * \leq 3.7[22,23]$. This range also depends on the manufacturer's criteria where the sample is slightly above 3.7. Based on the above, and according to Figure 3 , it is evident that the sample that would be considered clinically acceptable is sample B.

Figure 4 presents a series of SEM images collected from the porcelain cross-section. From this figure, it is possible to analyze the microstructure from 0 up to $2.5 \%$ (wt $\%$ ) of $\mathrm{Al}_{2} \mathrm{O}_{3}-3 \mathrm{Y}$-TZP particles. The observations indicated the presence of $3 \mathrm{Y}-\mathrm{TZP}, \mathrm{Al}_{2} \mathrm{O}_{3}$ particles or leucite phases in white contrast and the amorphous phase in dark contrast [11]. It also shows the interface, showing a good adhesion between the veneering and the substrate (red box). A homogeneous distribution of the particles of $\mathrm{Al}_{2} \mathrm{O}_{3}$ and $3 \mathrm{Y}$-TZP is observed, which means that there is no presence of agglomerates. In addition, the presence of porosity (circles) was found and it was greater than recorded by the standard sample.

\subsection{Mechanical characterization}

The results for Young's modulus obtained by nanoindentation, Vickers hardness and apparent fracture toughness by microindentation of porcelain VITA-VM9 and the new formulations are shown in the Table 4. It was observed that the new formulations showed a significant increase in hardness and fracture toughness in a range of 0.22-0.61 GPa and 0.1-0.18 $\mathrm{MPa} \sqrt{ } \mathrm{m}$, respectively. This increase is close to $11 \%$ in hardness and $18 \%$ in fracture toughness when compared to VITA-VM9. With respect to the Young's module, a decrease is observed at low percentages of material added, close to $8.97 \mathrm{GPa}$ (12\% compared to VITA-VM9), but an increase at high percentages of material added, about $1.76 \mathrm{GPa} \quad(2 \%$ compared to VITA-VM9).

Figures 5-7 show the distribution of Vickers hardness, Young's modulus and fracture toughness. These figures are a visual representation that describes the important characteristics of dispersion and symmetry in a data collection. The samples with addition of reinforcing agent 
Table 4 Young's modulus, hardness and tenacity for the veneerings

\begin{tabular}{llll}
\hline Name & $\mathbf{E}(\mathbf{G P a}) \pm \mathbf{S D}$ & $\mathbf{H V}(\mathbf{G P a}) \pm \mathbf{S D}$ & $\mathbf{K}_{\mathbf{c}}(\mathbf{M P a} \sqrt{\mathbf{m}}) \pm \mathbf{S D}$ \\
\hline Sample A & $70.47 \pm 0.45$ & $5.67 \pm 0.11$ & $1.00 \pm 0.06$ \\
Sample B & $61.50 \pm 0.53$ & $5.89 \pm 0.19$ & $1.10 \pm 0.06$ \\
Sample C & $72.23 \pm 0.52$ & $6.28 \pm 0.28$ & $1.18 \pm 0.05$ \\
\hline
\end{tabular}

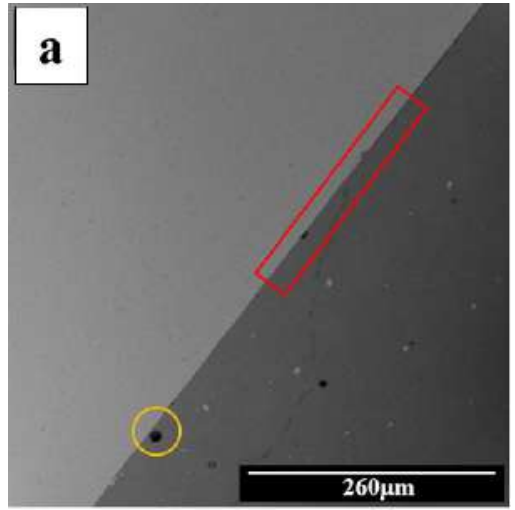

(a)

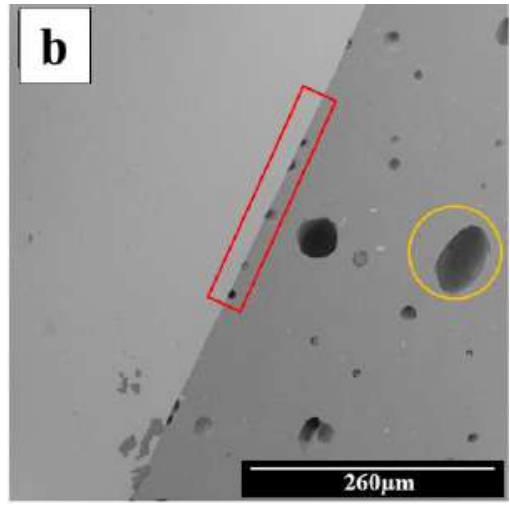

(b)

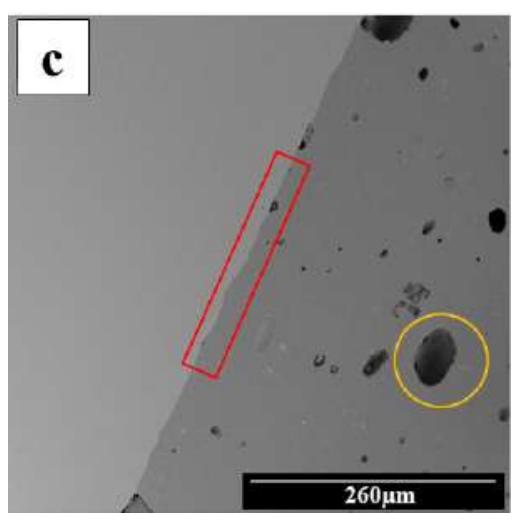

(c)

Figure 4 SEM image of the formulations with identification of the interface, crystalline phase and particles of $\mathrm{Al}_{2} \mathrm{O}_{3}-3 \mathrm{Y}-\mathrm{TZP}$. al

Sample A, b) Sample B and c) Sample C

present a statistically significant difference with respect to the fracture toughness and to the Young's modulus of the
VITA-VM9, although there is no significant difference with respect to the hardness.

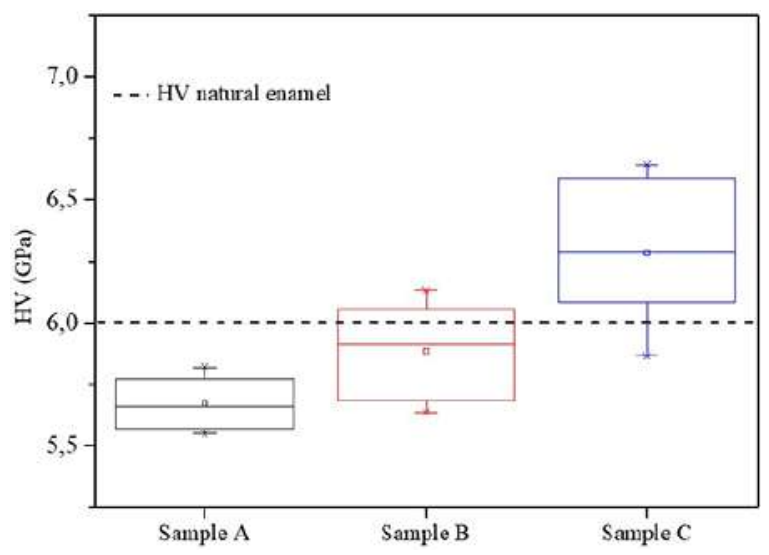

Figure 5 Box diagrams for Vickers hardness in the veneerings with addition of reinforcing agents 10.5 and $2.5 \%$ of $\mathrm{Al}_{2} \mathrm{O}_{3}-3 \mathrm{Y}-\mathrm{TZ} \mathrm{P}$ ) respect to VITA-VM9

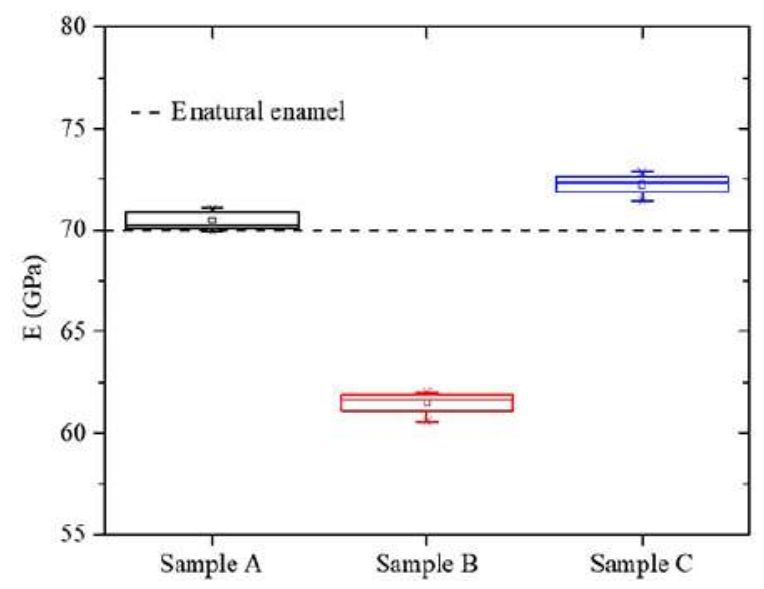

Figure 6 Box diagrams for Young's modulus in the veneerings with addition of alumina reinforcing agents 10.5 and $2.5 \%$ of $\mathrm{Al}_{2} \mathrm{O}_{3}-3 \mathrm{Y}-\mathrm{TZP}$ ) respect to VITA-VM9

In order to evaluate the influence of the amount of reinforcing agent on the hardness, Young's modulus and fracture toughness, an unifactorial analysis through ANOVA for the alumina factor was carried out by using the $\mathrm{R}$ commander software. A comparison was made for each of the levels $10,0.5$ and 2.5, with 0 being the VITA-VM9 sample), as shown in Tables 5-7. Establishing 


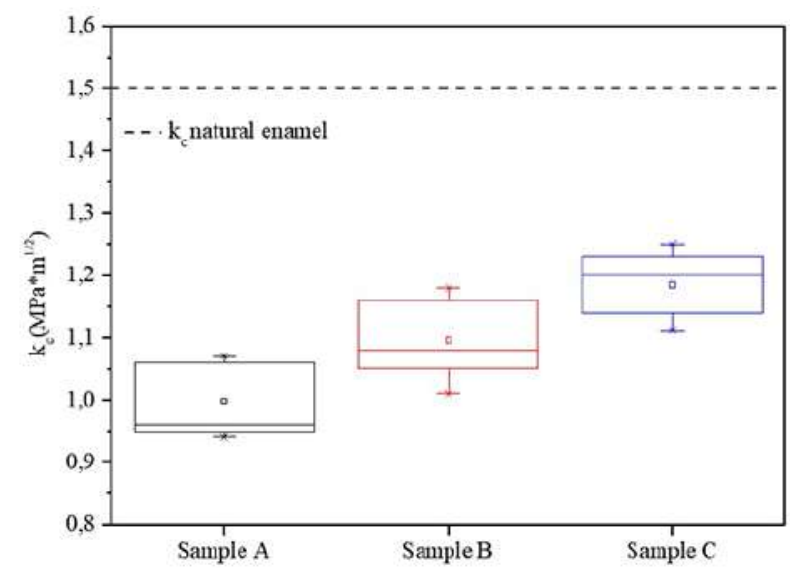

Figure 7 Box diagrams for fracture toughness in the veneerings with addition of alumina reinforcing agents $(0.5$ and $2.5 \%$ of $\mathrm{Al}_{2} \mathrm{O}_{3}-3 \mathrm{Y}-\mathrm{TZP}$ ) respect to VITA-VM9

a significance level $(\alpha)$ of 0.05 and since the P-value of the percentage factor is less than the significance level, it was observed that the hardness, Young's modulus and fracture toughness are strongly influenced by the amount of reinforcing agent added.

Table 5 ANOVA for the Vickers hardness values obtained from the veneerings with the addition of reinforcing agents 10.5 and $2.5 \%$ of $\mathrm{Al}_{2} \mathrm{O}_{3}-3 \mathrm{Y}-\mathrm{TZP}$ ) with respect to the VITA-VM9

\begin{tabular}{llllll}
\hline & Df & $\begin{array}{l}\text { Sum } \\
\text { Sq }\end{array}$ & $\begin{array}{l}\text { Mean } \\
\text { Sq }\end{array}$ & $\begin{array}{l}\text { F } \\
\text { value }\end{array}$ & P-value \\
\hline Percentage & 2 & 1.3584 & 0.6792 & 15.8 & 0.000109 \\
Residuals & 18 & 0.7739 & 0.0430 & & \\
\hline
\end{tabular}

Table 6 ANOVA for the Young's modulus values obtained from the veneerings with the addition of reinforcing agents 10.5 and $2.5 \%$ of $\mathrm{Al}_{2} \mathrm{O}_{3}-3 \mathrm{Y}-\mathrm{TZP}$ ) with respect to the VITA-VM9

\begin{tabular}{llccll}
\hline & Df & $\begin{array}{l}\text { Sum } \\
\text { Sq }\end{array}$ & $\begin{array}{l}\text { Mean } \\
\text { Sq }\end{array}$ & $\begin{array}{l}\mathbf{F} \\
\text { value }\end{array}$ & P-value \\
\hline Percentage & 2 & 463.8 & 231.92 & 928.7 & $<2 \mathrm{e}-16$ \\
Residuals & 18 & 4.5 & 0.25 & & \\
\hline
\end{tabular}

In order to validate the resultant models of the ANOVA, the residuals were calculated and the verification of the assumptions of normality, homoscedasticity and independence was carried out.

Figure 8 shows that the residuals come from a normal distribution for hardness, Young's modulus and fracture toughness. All the data are within the confidence interval represented by the discontinuous lines, this is corroborated by means of the shapiro-Wilk normality test whose results are reported in Tables 8-10. In this case the $\mathrm{P}$-value is greater than the significance level $\alpha=0.05$, therefore it is statistically confirmed that the residual data come from a normal distribution.

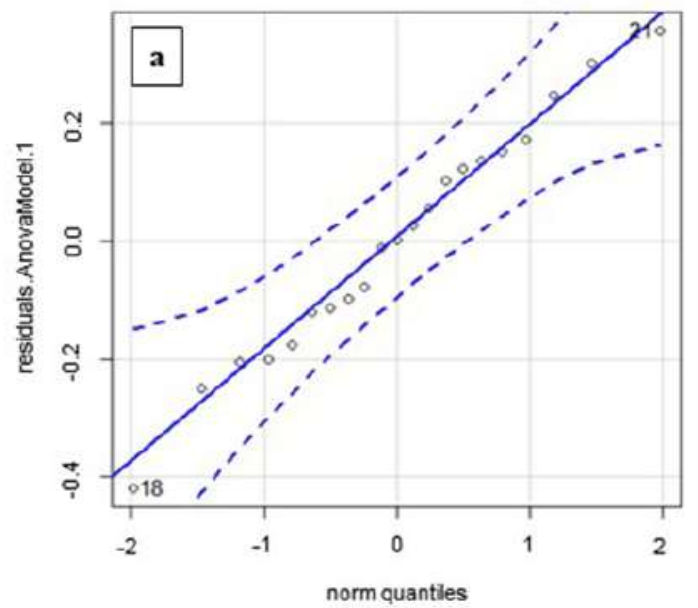

(a)

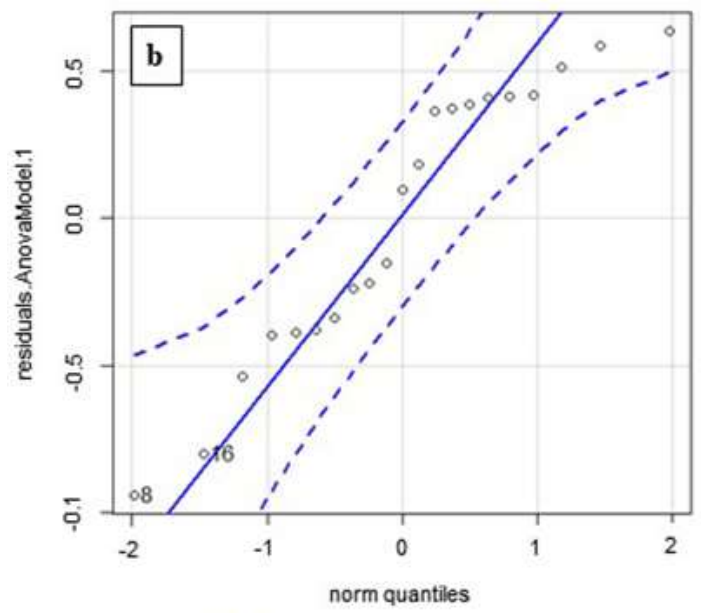

(b)

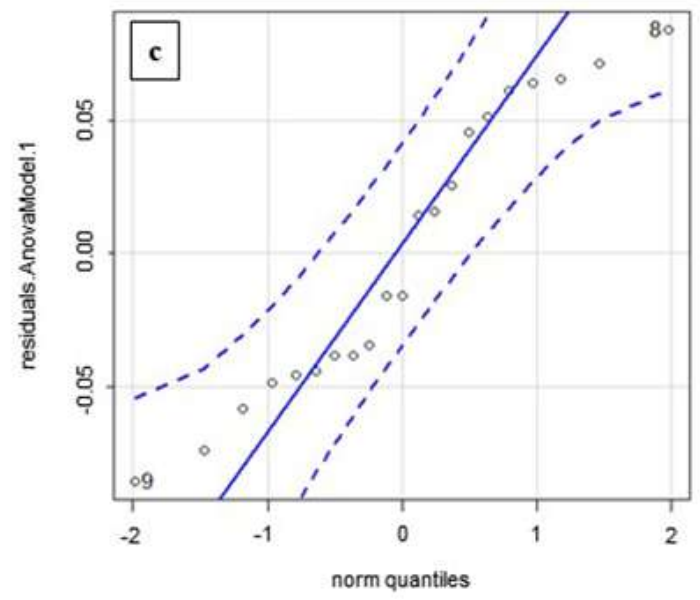

(c)

Figure 8 Constant variance. a) hardness, b) Young's modulus and c) fracture toughness 
Table 7 ANOVA for the fracture toughness values obtained from the veneerings with the addition of reinforcing agents 10.5 and 2.5 $\%$ of $\mathrm{Al}_{2} \mathrm{O}_{3}-3 \mathrm{Y}-\mathrm{TZP}$ ) with respect to the VITA-VM9

\begin{tabular}{lllccl}
\hline & Df & Sum Sq & Mean Sq & F value & P-value \\
\hline Percentage & 2 & 0.12080 & 0.0604 & 18.87 & 0.0000382 \\
Residuals & 18 & 0.05763 & 0.0032 & & \\
\hline
\end{tabular}

Table 8 Shapiro-Wilk normality test for hardness

\begin{tabular}{ll}
\hline Value & Data \\
\hline W & 0.98639 \\
P-value & 0.9868 \\
\hline
\end{tabular}

Table 9 Shapiro-Wilk normality test for Young's modulus

\begin{tabular}{ll}
\hline Value & Data \\
\hline W & 0.91898 \\
P-value & 0.08281 \\
\hline
\end{tabular}

Table 10 Shapiro-Wilk normality test for fracture toughness

\begin{tabular}{ll}
\hline Value & Data \\
\hline W & 0.92483 \\
P-value & 0.1084 \\
\hline
\end{tabular}

Figure 9 shows that the data have a good dispersion which may indicate that the variance is constant. This information is confirmed statistically by the Bartlett test whose results are reported in the Tables 11-13. In this case the $\mathrm{P}$-value is greater than the significance level $\alpha=0.05$, therefore homoscedasticity is fulfilled.

Table 11 Bartlett's homocedasticity test for hardness

\begin{tabular}{ll}
\hline Value & Data \\
\hline Bartlett's & 4.821 \\
k-squared & 2 \\
df & 0.08977 \\
P-value & \\
\hline
\end{tabular}

Table 12 Bartlett's homocedasticity test for Young's modulus

\begin{tabular}{ll}
\hline Value & Data \\
\hline Bartlett's & 0.17557 \\
k-squared & 2 \\
df & 0.916 \\
P-value & \\
\hline
\end{tabular}

From figure 10 can be inferred that the residuals do not present a correlation, as opposed to the first line, none of them exceeds the limits proposed by the discontinuous lines. To confirm this information, the Durbin-Watson independence test was carried out. The P-value (Tables 14-16) is greater than the degree of significance $\alpha=0.05$, so it is confirmed that there is no correlation between

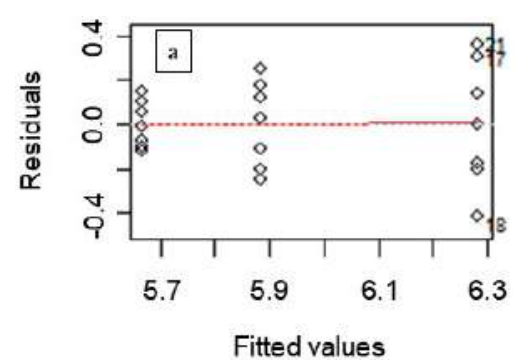

(a)

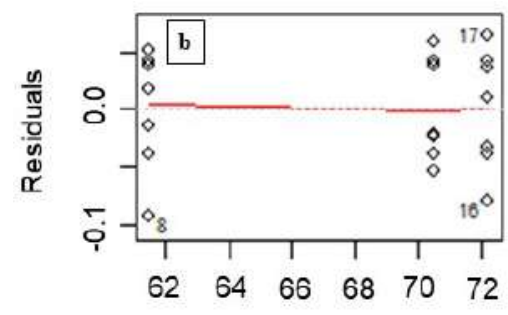

Fitted values

(b)

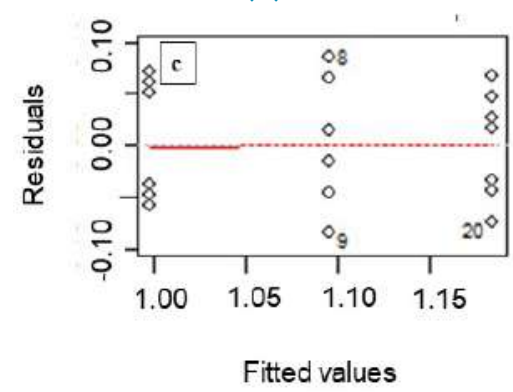

(c)

Figure 9 Bartlett Homocedasticity. al hardness, b) Young's modulus and c) fracture toughness

Table 13 Bartlett's homocedasticity test for fracture toughness

\begin{tabular}{ll}
\hline Value & Data \\
\hline Bartlett's & 0.98639 \\
k-squared & 2 \\
df & 0.9366 \\
P-value & \\
\hline
\end{tabular}

residuals, that is to say, they are independent values in time.

Given the above analysis, the models of hardness, Young's modulus and fracture toughness were validated, since the data meet the three assumptions: normality, 


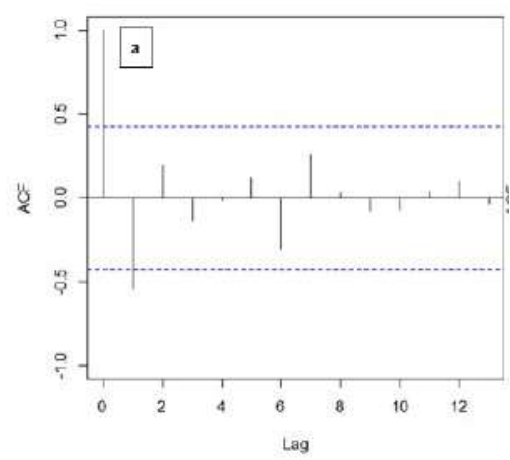

(a)

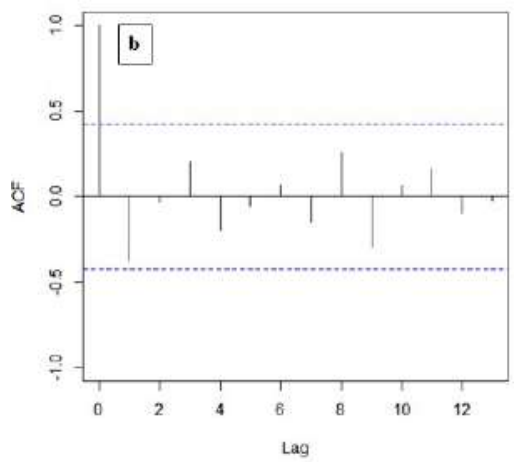

(b)

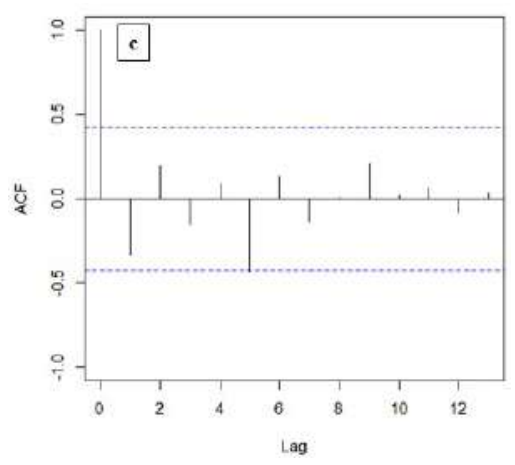

(c)

Figure 10 Independence of residuals. al hardness, b) Young's modulus and c) fracture toughness

Table 14 Durbin-Watson independence test for hardness

\begin{tabular}{ll}
\hline Value & Data \\
\hline DW & 2.9171 \\
P-value & 0.06681 \\
\hline
\end{tabular}

Table 15 Durbin-Watson independence test for Young's modulus

\begin{tabular}{ll}
\hline Value & Data \\
\hline DW & 2.685 \\
P-value & 0.2276 \\
\hline
\end{tabular}

Table 16 Durbin-Watson independence test for fracture toughness

\begin{tabular}{ll}
\hline Value & Data \\
\hline DW & 2.6199 \\
P-value & 0.2987 \\
\hline
\end{tabular}

homoscedasticity and independence.

Tables 17-19 show the values obtained from the comparison by pairs of the percentages of agent added. For hardness values, the P-value is less than the significance level $(\alpha)$ in the comparison by pairs $0-2.5$ and 0.5-2.5. On the other hand, the P-value is greater than the level of significance in the comparison by pairs 0 - 0.5. For the Young's modulus and fracture toughness values, the $\mathrm{P}$-values are less than the significance level $(\alpha)$ in the comparison by pairs $0.5-0,2.5-0$ and $2.5-0.5$. Therefore, hardness, Young's modulus and fracture toughness present an increase to higher percentage of material added of mixture. This increase is related to several hardening mechanisms that may be present, such as crack deflection, microcracking and energy absorption through plastic deformation and fracture of the reinforcing material $[6,24,25]$. This finding is in accordance with other studies that analyzed higher percentages of reinforcing agents of up to $30 \%$ [25-27].

Table 17 Tukey comparison test of hardness for the samples with the addition of reinforcing agents 10.5 and $2.5 \%$ of $\mathrm{Al}_{2} \mathrm{O}_{3}-3 \mathrm{Y}$-TZP) with respect to the VITA-VM9

\begin{tabular}{lllll}
\hline Comparison & Estimate & Error & T value & P-value \\
\hline $0.5-0$ & 0.2161 & 0.1108 & 1.950 & 0.1539 \\
$2.5-0$ & 0.6141 & 0.1108 & 5.541 & $<0.001$ \\
$2.5-0.5$ & 0.3980 & 0.1108 & 3.591 & 0.0056 \\
\hline
\end{tabular}

Table 18 Tukey comparison test of Young's modulus for the samples with the addition of reinforcing agents 10.5 and $2.5 \%$ of $\mathrm{Al}_{2} \mathrm{O}_{3}-3 \mathrm{Y}$-TZP) with respect to the VITA-VM9

\begin{tabular}{lllll}
\hline Comparison & Estimate & Error & T value & P-value \\
\hline $0.5-0$ & -8.9724 & 0.2671 & -33.589 & $<0.00001$ \\
$2.5-0$ & 1.7600 & 0.2671 & 6.589 & $<0.00001$ \\
$2.5-0.5$ & 10.7325 & 0.2671 & 40.178 & $<0.00001$ \\
\hline
\end{tabular}

Table 19 Tukey comparison test of fracture toughness for the samples with the addition of reinforcing agents 10.5 and $2.5 \%$ of $\mathrm{Al}_{2} \mathrm{O}_{3}-3 \mathrm{Y}$-TZP) with respect to the VITA-VM9

\begin{tabular}{lllll}
\hline Comparison & Estimate & Error & T value & P-value \\
\hline $0.5-0$ & 0.09714 & 0.03024 & 3.212 & 0.0128 \\
$2.5-0$ & 0.18571 & 0.03024 & 6.140 & $<0.001$ \\
$2.5-0.5$ & 0.08857 & 0.03024 & 2.928 & 0.0231 \\
\hline
\end{tabular}




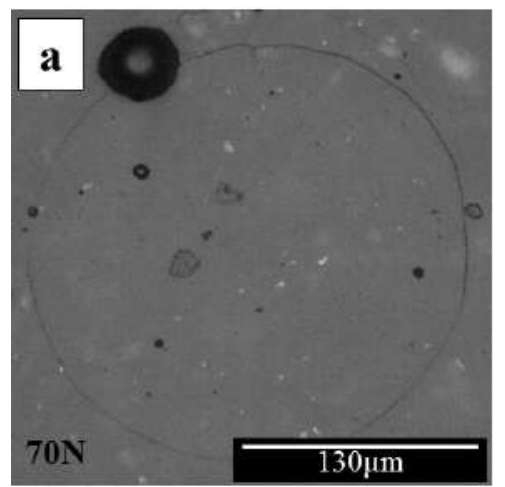

(a)

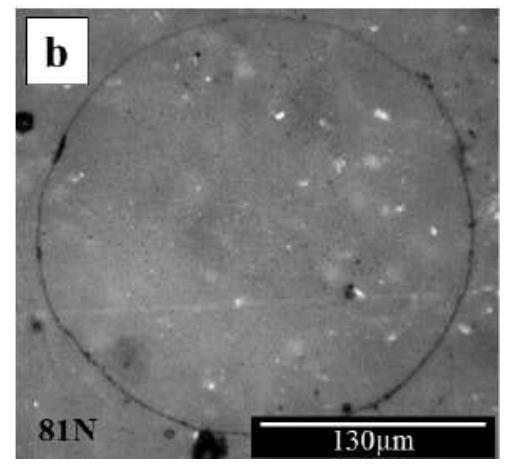

(b)

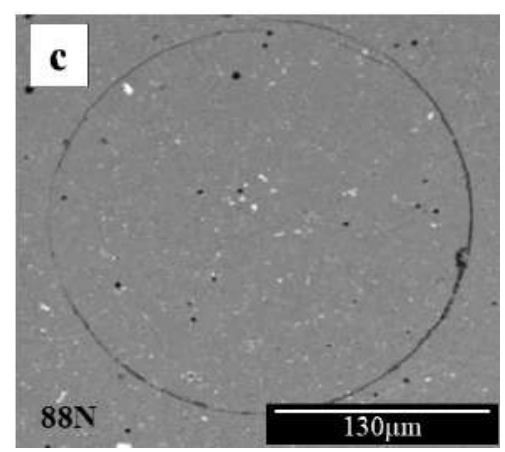

(c)

Figure 11 Monotonic Hertzian contact damage in the veneering of porcelain formulations. A) Sample A, b) Sample B and c) Sample C

On the other hand, it was observed that the values obtained for hardness, Young's modulus and fracture toungness were within the values reported for natural enamel [28]. It would be expected that in the long term the wear of the tooth that is in contact with this modified porcelain would be very similar to that presented between tooth-tooth.

In order to investigate the influence of deformation, bulk samples were subject to Hertzian monotonic contact, which allow to simulate the chewing conditions. It was possible to observe that the first detectable damage was ring cracking $[18,19]$. When the critical load to which this first damage appears (ring crack), can be generated multiple surface frictions that modify the stress field and promotes the formation of catastrophic cracks in the material.

Figure 11 shows the formation of the complete damage ring cracking at a load range between 66 to $88 \mathrm{~N}$, these cracks are within the range of normal chewing loads $[14,29]$. At $66 \mathrm{~N}$, sample A recorded the first completely damaged ring, whereas, under that load, the other formulations did not show this criterion. In none of the samples was there evidence of radial cracks, appreciable plastic deformation nor any superficial collapse of the material. Also, at the interface no cracks or damage was observed, indicating that this area is not a critical point of failure during contact loading. Finally, it was observed that the sample $C$ is the one that presents a better behavior against the monotonic Hertzian contact.

Despite the increase observed for the fracture toughness and contact resistance in the $\mathrm{C}$ sample, it is necessary to mention that the increase of the porosity lead to a loss of these properties.

\section{Conclusions}

In this study, the microstructure and mechanical properties of porcelain formulations containing up to $2.5 \%$ (wt) $\mathrm{Al}_{2} \mathrm{O}_{3}-3 \mathrm{Y}$-TZP mixture were fabricated and tested. The use of a sonicator for the preparation of the new formulations provided a good homogenization of the mixtures. This procedure allowed to obtain good adhesion between the veneering and the substrate in all the formulations. There were evidenced changes in the translucency and in the porosity of the new formulations with respect to the standard sample (VITA-VM9 porcelain). The addition of $\mathrm{Al}_{2} \mathrm{O}_{3}-3 \mathrm{Y}$-TZP mixture phase showed to improve the overall mechanical properties of porcelain. Moreover, the highest values of hardness, Young's modulus, fracture toughness and contact response were found for composites with addition of $\mathrm{Al}_{2} \mathrm{O}_{3}-3 \mathrm{Y}$-TZP $2.5 \%$ wt mixture. The enhanced properties displayed by such composites cannot provide a high performance for dental prostheses without altering the aesthetics of the material.

\section{Acknowledgments}

The authors are grateful to Universidad Eafit for the J. Gómez master's scholarship and to the grant received by Colciencias through the program "Es tiempo de volver" awarded to A. O. Rueda. 


\section{References}

[1] Z. R. Zhou and J. Zheng, "Tribology of dental materials: a review," J. Phys. D. Appl. Phys., vol. 41, no. 1, p. 113001, 2008.

[2] K. J. Anusavice, "Degradability of dental ceramics," Adv. Dent. Res., vol. 6, pp. 82-89, Sep. 1992.

[3] J. L. Ong, D. W. Farley, and B. K. Norling, "Quantification of leucite concentration using x-ray diffraction," Dental Materials, vol. 16, no. 1, pp. 20-25, Jan. 2000.

[4] M. Peumans, B. V. Meerbeek, P. Lambrechts, and G. Vanherle, "Porcelain veneers: a review of the literature," Journal of Dentistry, vol. 28, no. 3, pp. 163-177, Jan. 2000.

[5] M. Balkenhol and et al., "Bonding to zirconia ceramic: The effect of cold plasma treatment and 4-meta," Clinical Plasma Medicine, vol. 5-6, pp. 8-13, Jun. 2017.

[6] I. S. Medeiros, L. A. Luz, H. N. Yoshimura, P. F. Cesar, and A. C. Hernandes, "Al203/GdAlO3 fiber for dental porcelain reinforcement," Journal of the Mechanical Behavior of Biomedical Materials, vol. 2, no. 5, pp. 471-477, Oct. 2009.

[7] J. W. Kim, M. N. Janal, J. H. Kim, and Y. Zhang, "Damage maps of veneered zirconia under simulated mastication," J. Dent. Res., vol. 87, no. 12, pp. 1127-1132, Jan. 2008.

[8] M. V. Swain, "Unstable cracking (chipping) of veneering porcelain on all-ceramic dental crowns and fixed partial dentures," Acta Biomaterialia, vol. 5, no. 5, pp. 1668-1677, Jun. 2009.

[9] R. Sgura, I. Studart, P. F. Cesar, A. Almeida, and A. C. Hernandes, "Porcelain monolayers and porcelain/alumina bilayers reinforced by Al203/GdAlO3 fibers," Journal of the Mechanical Behavior of Biomedical Materials, vol. 5, no. 1, pp. 110-115, Jan. 2012.

[10] M. J. Tholey, M. V. Swain, and N. Thiel, "Sem observations of porcelain y-tzp interface," Dental Materials, vol. 25, no. 7, pp. 857 862, Jul. 2009.

[11] R. L. P. Santos and et al., "On the mechanical properties and microstructure of zirconia-reinforced feldspar-based porcelain," Ceramics International, vol. 42, no. 12, pp. 14214-14221, Sep. 2016.

[12] F. Martínez, G. Pradíes, M. Suárez, and B. Rivera, "Cerámicas dentales: clasificación y criterios de selección," RCOE, vol. 12, no. 4, pp. 253-263, Oct. 2017

[13] P. H. Kumar, V. Singh, P. Kumar, G. Yadav, and R. K. Chaturvedi, "Effect of Al2O3 on leucite based bioactive glass ceramic composite for dental veneering," Ceram. Int., vol. 42, no. 2, Part B, pp. 3591-3597, Oct. 2016.

[14] VITAVM9 Instrucciones de uso, Versión 09.11, VITA, 2011.

[15] P. C. Guess and et al., "Shear bond strengths between different zirconia cores and veneering ceramics and their susceptibility to thermocycling," Dental Materials, vol. 24, no. 11, pp. 1556-1567, Nov.
2008.

[16] C. Rivera, D. Arola, and A. Ossa, "Indentation damage and crack repair in human enamel." J. Mech. Behav. Biomed. Mater., vol. 21, pp. 178-84, May 2013.

[17] I. M. Peterson, A. Pajares, B. R. Lawn, V. P. Thompson, and E. D. Rekow, "Mechanical characterization of dental ceramics by hertzian contacts," J. Dent. Res., vol. 77, no. 4, pp. 589-602, Apr. 1998.

[18] A. O. Rueda, J. Seuba, M. Anglada, and E. Jiménez, "Tomography of indentation cracks in feldspathic dental porcelain on zirconia," Dental Materials, vol. 29, no. 3, pp. 348-356, Mar. 2013.

[19] A. O. Rueda, M. Anglada, and E. Jimenez, "Contact fatigue of veneer feldspathic porcelain on dental zirconia," Dent. Mater., vol. 31, no. 3 , pp. 217-224, Mar. 2015.

[20] ISO 11664-4: 2008 (E) / CIE S 014-4 / E: 2007 - Colorimetry - Part 4: CIE $1976 L{ }^{*} A * B *$ Color Space, ISO 11664-4, 2008.

[21] K. Haas, G. Azhar, D. J. Wood, K. Moharamzadeh, and R. van Noort, "The effects of different opacifiers on the translucency of experimental dental composite resins," Dental Materials, vol. 33 , no. 8, pp. e310-e316, Aug. 2017.

[22] B. Uludag, A. Usumez, V. Sahin, K. Eser, and E. Ercoban, "The effect of ceramic thickness and number of firings on the color of ceramic systems: An in vitro study," J. Prost. Dent., vol. 97, no. 1, pp. 25-31., Jan. 2007

[23] I. Sarikaya and A. U. Güler, "Effects of different surface treatments on the color stability of various dental porcelains," Journal of Dental Sciences, vol. 6, no. 2, pp. 65-71, Jun. 2011.

[24] P. F. Cesar, H. N. Yoshimura, W. G. Miranda, and C. Y. Okada, "Correlation between fracture toughness and leucite content in dental porcelains," Journal of Dentistry, vol. 33, no. 9, pp. 721-729, Oct. 2005.

[25] M. Kon, K. Ishikawa, and N. Kuwayam, "Effects of zirconia addition on fracture toughness and bending strength of dental porcelains," Dent. Mater. J., vol. 9, no. 2, pp. 181-92, Dec. 1990.

[26] M. Kang and et al, "Synthesis and properties of dental zirconia-leucite composites," Bull. Mater. Sci., vol. 33, no. 6, pp. 713-717, Dec. 2010.

[27] V. Frith, R. O. Heckroodt, and K. H. Schueller, "Mechanical properties of zircon-feldspar porcelains," CFI Ceramic Forum International, vol. 64, no. 10, pp. 379-383, 1987.

[28] C. A. Rivera, A. Ossa, and D. Arola, "Fragilidad y comportamiento mecánico del esmalte dental," Rev. Ing. Biomédica, vol. 6, no. 12, pp. 10-16, 2012.

[29] J. W. Kim, J. H. Kim, and Y. Zhang, "Sliding contact fatigue damage in layered ceramic structures," J. Dent. Res., vol. 86, no. 11, pp. 1046-50, Nov. 2007. 